\title{
La huella de Boccaccio en el Renacimiento español y la recepción de Le piacevoli notti de Straparola
}

\author{
Marco FEDERICI \\ Università degli Studi di Napoli "L’Orientale" \\ mfederici@unior.it
}

\section{RESUMEN}

Las novelle italianas de Boccaccio y Straparola traducidas al castellano tuvieron mucho éxito en la literatura y en el teatro del Siglo de Oro, y los traductores las adaptaron según el clima cultural de la época. El trabajo de traducción del Decameron y de Le piacevoli notti presenta parecidos en muchas partes, como en las enmiendas de contenidos obscenos o en la introducción de elementos textuales nuevos; en el caso de Truchado hay atisbos de que intenta escaparse del control, escondiendo asuntos prohibidos como la magia (por ejemplo en las tropelías) y la alusión erótica (como en los enigmas).

Palabras clave: Straparola, Truchado, censura, novela corta, traducción

\begin{abstract}
Boccaccio and Straparola's italian short novels translated into Castilian were successfully accepted in the Golden Age literature and theater; their translators adapted them according to their country's cultural background. The translations of the Decameron and Le piacevoli notti resemble in many places, as in obscene subject amendments or in new textual elements introductions; we notice Truchado's intention to get away from the control, hiding banned issues like magic (for example in the tropelias) and erotic innuendo (as in the riddles).
\end{abstract}

Key words: Straparola, Truchado, censure, short novel, translation

La estela de Giovanni Boccaccio en la España renacentista, y aún más en Europa, distingue al escritor de Certaldo - junto con Petrarca- como padre y mito pujante y renovador del Renacimiento: por primera vez obras literarias de alto valor corrían impetuosamente a lo largo del continente viejo traducidas en otras lenguas vulgares y en latín ${ }^{1}$. Sabemos que la España del Siglo XV no conoció a Boccaccio

${ }^{1}$ V. Branca (2001), p. 24. 
por su Decameron, aunque en la Biblioteca de Catalunya se guarde un manuscrito de la traducción catalana de 1429 (MS 1716). Después de una edición sevillana de 1496 por los impresores Meinardo Ungut y Estanislao Polono, el Decameron tuvo cuatro apariciones más en la primera mitad del siglo XVI (Toledo, Juan de Villaquirán, 1524; Valladolid 1539; Medina del Campo, Pedro de Castro, a costa de Juan de Espinosa 1543; Valladolid 1550)², y terminó incluido algunos años más tarde en el índice de Valdés (1559) y en el de Quiroga (1583) bajo la indicación «Novelas de Ioan Bocacio». La prohibición de sus novelas en España duró casi dos siglos, si bien en Florencia se publicó una edición del Decameron expurgada según las normas tridentinas, que vio la luz en 1573 y fue la única admitida en España ${ }^{3}$.

Siempre a propósito de la recepción, Carlos Alvar señala que unas referencias al certaldés aparecieron ya en la poesía de Cancionero de los siglos XV y XVI, donde algunos poetas se refieren principalmente al De casibus y al Corbacho, y en la Comedieta de Ponça del Marqués de Santillana ${ }^{4}$. María Jesús Lacarra recuerda además la heterogénea acogida de las obras de Boccaccio en España, y añade que, pese a su temprana presencia en la península ibérica, las novelle no se imitaron en castellano hasta mediados del siglo XVI, y sólo en el XVII el Decameron será una de las mayores fuentes de piezas teatrales ${ }^{5}$. Las causas de este largo retraso -sigue opinando la estudiosa- deben imputarse al contenido profano y obsceno de las novelas italianas, que se alejaba de la tradición medieval. Esta dilación de la recepción literaria, y la presencia de cinco ediciones hasta la primera prohibición valdesiana, parece dar vida a una exitosa difusión en italiano y en español de las obras de otros novellieri que, partiendo del modelo del Decameron, fueron admitidos favorablemente por el público español.

No sólo Boccaccio sino diferentes novellieri se tradujeron en España parcial o totalmente: es el caso de Matteo Bandello, Giovan Battista Giraldi Cintio, Ludovico Guicciardini y Giovan Francesco Straparola ${ }^{6}$. Otros nombres de menor relevancia

${ }^{2}$ Datos extraídos de J.M. Lucía Megías y V. Sama Rojo (2001), p. 581.

${ }^{3}$ G. Güntert (2001), p. 681.

${ }^{4}$ C. Alvar (2001), pp. 333-350. A propósito de la relación con Santillana véase M.Á.Pérez Priego (2001).

${ }^{5}$ M.J. Lacarra (2001), p. 393.

${ }^{6}$ Según M. Menéndez y Pelayo (1962), vol. III, p. 34, Matteo Bandello siguió al Boccaccio como importancia y éxito en España. De Arróniz (1969) aprendemos que sus novelle fueron la base de la Patraña Séptima de Timoneda, extraída de la novella 44 de la Segunda Parte de su obra. Las Hecatommithi de Giraldi Cintio también tuvieron un destino favorable, al ser por ejemplo la fuente inspiradora del Piadoso veneciano de Lope de Vega. J.M. Pedrosa (2004) señala que, posiblemente, después de Boccaccio el novelliere de mayor influencia fue Poggio Bracciolini con su Liber Facetiarum (pp. 45-46). Guarino (1993) también le da un papel importante a Bracciolini, indicando en la corriente renacenista nacida del Liber facetiarum un directo antecedente de la «miscela proposta da Timoneda nel Sobremesa e nel Buenaviso» (pp. 10-11). 
podrían añadirse a esos ya citados. La escasez en el número de ediciones no debe ser tomada como índice de la influencia de estos autores en las obras españolas, que fue altísima. Hay que añadir que muchos españoles leían en italiano, y juzgaban de baja calidad las traducciones de sus connacionales. El influjo de la novella en España se observa en los imitadores, que reelaboran los temas italianos y los interpolan en sus obras adaptándolos a la cultura española. Joan Timoneda es un ejemplo de lo que acabamos de decir: en la epístola al lector del Sobremesa admite haber reunido «lo que yo en diversos años he oído, visto y leído»; en cambio, en $E l$ patrañuelo ajusta casi hasta el plagio tres cuentos de Boccaccio (II, XV e XII), y demuestra haber leído a Bandello y a Sabatino degli Arienti ${ }^{7}$.

Boccaccio y los demás novellieri mantuvieron su prestigio e influencia también en la novela cortesana, que dispuso de la aportación del Decameron o de los cuentos de Bandello y de Giraldi Cintio ${ }^{8}$. Estos tres autores siguieron siendo un punto de referencia para los escritores del siglo XVII: hablando de teatro, recordamos la deuda de Lope de Vega hacia ellos ${ }^{9}$.

Le piacevoli notti de Straparola tuvieron larga vida editorial en Italia, al salir más de veinte ediciones entre 1550 -fecha en la que vio la luz la princeps del Libro Primero- y $1608^{10}$. La traducción de Francisco Truchado, el Honesto y agradable entretenimiento de damas y galanes, se publicó en la segunda mitad del siglo XVI y siguió su tradición impresa hasta 1612: hoy día contamos con ocho ediciones a partir de $1578^{11}$. El traductor, vecino de Baeza y bedel en la Universidad de la

\footnotetext{
${ }^{7}$ A. Guarino (1993), pp. 10 y 56.

${ }^{8}$ A. González de Amezúa (1929), p. 148.

${ }^{9}$ Véanse sobre Giovanni Boccaccio: C.B. Bourland (1905); J.C.J. Metford (1952); C. Segre (1975). Sobre Matteo Bandello véase E. Levi (1935) y también A. Gasparetti (1939); G. Bradbury (1980); A. Alonso (1993). Sobre Giraldi Cintio véanse A. Gasparetti (1930); E. Kohler (1946); I. Romera Pintor (2000) y J.M. Pedrosa (2004), que indica que entre las comedias de Lope, las que toman inspiración de las Hecathommithi de Cintio son La discordia en los casados; La cortesía de España; El piadoso veneciano; Servir a señor discreto; El villano en su rincón y El mayordomo de la duquesa de Amalfi (p. 48).

${ }^{10}$ Para profundizar el tema de la tradición impresa de la obra de Straparola véase D. Pirovano (2000 y 2001) y Straparola (2000), pp. LV-LXIII. Un análisis del contexto renacentista, de las obras parecidas de otros escritores italianos y del juicio de la crítica, se halla en Straparola (2000), pp. IX-L.

${ }^{11}$ El importante hallazgo de esta edición de Zaragoza de 1578 se anuncia en D. González Ramírez (2011a). La primera edición moderna del texto traducido por Truchado es mi tesis doctoral M. Federici (2011). Este trabajo ha sido ahora publicado (F. Truchado [2014]) y actualizado, ofreciendo también el cotejo de la editio princeps que faltaba en la tesis por no haber localizado el impreso aragonés.
} 
misma ciudad, se demuestra hombre acostumbrado a la traducción, y está documentado que también manejó una obra de Sabba da Castiglione ${ }^{12}$.

Como el Decameron, la recopilación de Straparola fue un excelente punto de partida y de referencia para la narrativa breve y el teatro del Siglo de Oro, mostrando estrechas relaciones con obras anteriores como La lozana andaluza (1528), o dejando su huella en algunos de los más importantes textos literarios españoles de este siglo, como El patrañuelo (1567) y el Guzmán de Alfarache (1599-1604), demostrando también una sucinta relación con el episodio del robo del asno en el Quijote o bien con la novela ejemplar del celoso extremeño ${ }^{13}$; a pesar de esto, el interés de la crítica es reciente ${ }^{14}$.

${ }^{12}$ Sabba da Castiglione, Parte primera del Cauallero Auisado: en la q[ua]l con prudente y
Christiano discurso, se tracta d[e] todo lo que deue hazer el hombre para ser auisado,
Compuesta por Monseñor d[e] Sabaa [sic], Castellon: cauallero d[e] la orden d[e] sant
Iuan; y traduzida por Francisco Truchado, Impresso en Baeça, en casa d[e] Iuan Baptista de
Montoya, 1585: trad. de Ricordi ovvero ammaestramenti, nei quali con prudenti e christiani
discorsi si ragiona di tutte le materie honorate che si ricercano a un vero gentil huomo. Sobre Truchado y esta segunda traducción véase N. Baranda (2001). De P.M. Cátedra (2001) proceden los datos biográficos sobre el oficio de bedel en la Universidad de Baeza.

${ }^{13} \mathrm{La}$ comparación entre una novela de Straparola -VI:1 en la italiana, VIII:3 en la traducción española- y un episodio de La lozana andaluza a partir del tema de la pérdida del anillo y el de la mujer embarazada estando el marido ausente se halla en J.M. Pedrosa (1995), pp. 253-256. Sobre la relación con Mateo Alemán véase E. Cros (1971), p. 68 y ss. Se ha señalado también que la Patraña Cuarta de Timoneda proviene de la novella IV:2 de Straparola en O. Arróniz (1969), p. 136 y A. Guarino (1993), p. 92. La posible conexión entre Le piacevoli notti y el Quijote ha sido subrayada en M. Federici (2010), donde se sugiere una fuente plausible al importante episodio del robo del asno de Sancho, que tiene un precedente muy parecido en una novella de Straparola (I:2) traducida al castellano. Ya sabemos que el acontecimiento del Quijote rememora algunos versos del Orlando innamorato, pero se ha demostrado que Cervantes no tomó inspiración de Boiardo. Hoy día este hallazgo en la recopilación italiana queda la única posible alternativa al épico acaecimiento del Innamorato. El tema de los celos entre Straparola, Bandello y Cervantes ha sido desarrollado en E. Di Pinto (1999).

${ }^{14}$ En primer lugar señalo a M. Federici (2011), tesis doctoral defendida el día 13 de mayo de 2011 y depositada en el Archivo digital PADIS el día 11 de agosto de 2011. De este largo trabajo de edición he publicado dos artículos: M. Federici (2010) - cf. nota 13- y M. Federici (2011a). Siguen D. González Ramírez (2011) y D. González Ramírez (2012). Entre sus investigaciones destaca el importante trabajo de D. González Ramírez (2011a). Lamento no poder contar con algunas aportaciones de Leonardo Coppola por su misma voluntad: quedamos a la espera de que se publiquen las actas de los congresos AISO 2011 y AISPI 2012, donde el investigador ha comunicado algunos resultados de sus estudios. Es preciso señalar que las actas AISO se publicaron cuando ya había entregado este mi trabajo, sin permitirme por esto la inclusión de más que esta nota bibliográfica. L. Coppola (2012) contiene en cambio una reflexión detallada sobre la dispositio del texto traducido por 
La estructura de la recopilación de Straparola recuerda mucho a la de las novelas de Boccaccio: como las del escritor de Certaldo -y según la tradición de la novellalos cuentos de Le piacevoli notti se encierran en un marco narrativo que, en este caso específico, coincide con los días de carnestolendas. Ottaviano Maria Sforza abandona Milán con su hija Lucrezia Gonzaga -desde 1523 viuda de Francesco Gonzaga, y que mucho recuerda a la figura de Pampinea- para huir de ciertas revoluciones internas en el Estado. Llegan a la cercana ciudad de Lodi -donde se quedan algunos días- hasta que descubiertos por sus perseguidores parten hacia Venecia, donde los acoge el mercader Ferier Beltramo. De Venecia llegan a la isla de Murano, y se alojan en un hermoso palacio con maravillosas habitaciones, un verde jardín con juegos de agua y un mirador que señorea aquella tierra. Será en este palacio donde tendrán lugar las noches de entretenimiento. Más que la riqueza de elementos pertenecientes a la tradición popular, lo que difiere entre las recopilaciones de Straparola y Boccaccio es la presencia de un enigma que en la primera cierra cada novella.

La traducción de Truchado parte de una edición veneciana de 1565 (Andrea Revenoldo y Giorgio de Zilli) o de 1567 (Iseppo di Mantelli), que ya había sido censurada antes por el impresor Orfeo Della Carta en 1555, cuando un cuento demasiado obsceno (VIII:4) había sido reemplazado por dos nuevos que ocupaban el mismo espacio tipográfico. Se crea así una anomalía en el orden acostumbrado, al contener la noche Octava seis cuentos en lugar de cinco ${ }^{15}$. Por supuesto Truchado tenía entre sus manos los dos volúmenes de Le piacevoli notti, porque en su Libro Primero se encuentran algunas novelle de la Segunda Parte italiana ${ }^{16}$. A partir de este testimonio veneciano, el traductor elige de manera tal vez arbitraria las novelle que verterá al español ${ }^{17}$. Este método de traducción del texto italiano se parece al

Truchado. Por último es reciente la aparición de E. Marcello (2012) y E. Marcello (2013). Esta última aportación coincide en algunas conclusiones con M. Federici (2011), a quien Elena Marcello no cita; la estudiosa tampoco tiene en cuenta el importantísimo hallazgo de la edición de 1578 por D. González, y por eso sigue afirmando que la princeps de la traducción de Truchado es de 1580.

${ }^{15}$ Sobre la censura de las ediciones italianas remito a D. Pirovano (2001). A propósito del impreso poseído por Truchado, los citados L. Coppola (2012) y E. Marcello (2013) afirman haber cotejado la edición italiana de 1565 conservada en la Biblioteca Nacional de París, sin hablar de la otra posible fuente de 1567. Coppola nos remite a un trabajo suyo en prensa, las actas del congreso AISO (2011) que, como queda dicho, no hemos podido consultar. La cuestión de la edición italiana que utilizó Truchado se halla también en el capítulo "La fonte italiana" de M. Federici (2011), vol. I, p. 127 y ahora en F. Truchado (2014), pp. 82-88 donde se ofrece también un cotejo parcial del impreso italiano de 1567 (pp. 85-87).

${ }^{16}$ Se trata de la VI:5 (desplazada en III:5); VIII:5 (desplazada en VI:1); X:5 (desplazada en V:2); XIII:1 (desplazada en V:5); XIII:2 (desplazada en IV:3); XIII:3 (desplazada en V:3); XIII:4 (desplazada en V:4).

${ }^{17}$ Para el estudio pormenorizado de la nueva disposición del texto véase L. Coppola (2012). 
que se usó con el Decameron: Pilar Gómez Bedate indica que esta obra «había sufrido enmiendas y abreviaciones que habían transmitido de él una visión parcial $\mathrm{y}$, por lo mismo, infiel a la intención primera $\iota^{18}$. Lo mismo dígase del manuscrito Esc J-II-21 (o sea la versión castellana más antigua de la obra de Boccaccio), códice guardado en la Biblioteca del Real Monasterio de San Lorenzo del Escorial que incluye una traducción parcial del Decameron: organizado en sesenta capítulos señala Mita Valvassori-, diez traducen la introducción y sólo cincuenta los cuentos, elegidos de forma aparentemente arbitraria ${ }^{19}$.

Por último, señalamos que Truchado añade elementos ajenos a la recopilación de Straparola, como por ejemplo la novela IX:5 que Doris Senn localizó entre las de Anton Francesco Doni $^{20}$. En realidad, hay que añadir que en 1852 Salvatore Bongi señalaba la presencia de esta narración en más obras renacentistas: se trata del Raverta, diálogo amoroso de Giuseppe Betussi (1544), de las rarísimas Lettere de Doni (sin indicar el año de edición) y de sus Pistolotti amorosi $(1552)^{21}$. Ahora la novela puede con cierta seguridad decirse traducida a partir del texto de esta última obra del escritor florentino ${ }^{22}$.

Pero hay más, porque la VI:2 de Truchado es también ajena a Le piacevoli notti y procede de la tradición castellana: se trata de una serie de octavas reales de Juan de Almeida (Toledo, 1542 - Salamanca, 1572) que se hallan en el manuscrito 3968 de la Biblioteca Nacional de Madrid (fols. 181v-182v) ${ }^{23}$. Debe considerarse ajena también la VII:1, por ser la continuación en prosa de las octavas precedentes.

Este expediente de interpolar elementos nuevos crea un paralelismo con el incunable sevillano de Las cien novelas de Juan Bocacio (1496), donde el cuento 73 no procede del Decameron sino que pertenece a una tradición ajena y desconocida todavía ${ }^{24}$. La elección de Truchado -que deja venticinco novelle sin traducir- se dirige hacia los cuentos que inflaman la fantasía del lector, y que a menudo contienen aquel elemento sobrenatural y mágico que los acerca a los cuentos orientales. Es posible que el público español valorara su carácter popular ${ }^{25}$.

La intención de transmitir un texto que no contenía peligrosos elementos susceptibles de censura parece indiscutible. Pero no sólo esto, porque al traducir la

\footnotetext{
${ }^{18}$ P. Gómez Bedate (2007), pp. 299-300.

${ }^{19}$ M. Valvassori (2010), p. 16.

${ }^{20}$ D. Senn (1993), p. 50.

${ }^{21}$ S. Bongi (1852), p. 173.

${ }^{22}$ Los resultados de mi investigación sobre esta novela ajena a la obra de Straparola, el cotejo de los citados textos de Betussi y de Doni, y la identificación de los Pistolotti amorosi como fuente textual se han presentado en M. Federici (2014).

${ }^{23}$ En este caso también remito a M. Federici (2014). Sobre Juan de Almeida véase M. Hernández Esteban (2009).

${ }^{24}$ M. Hernández Esteban (2002).

${ }^{25}$ J.M. Laspéras (1987), p. 91.
} 
obra Francisco Truchado parece cuidarse mucho de que desaparezca cualquier ambigüedad que podría insinuar al lector un sentido poco decoroso. El intento del baezano se declara a partir del título, al traducir el italiano Le piacevoli notti, arriesgado por equivocidad, con el más largo y menos enigmático Honesto y agradable entretenimiento de damas y galanes. Se trata de una perífrasis interpretativa que aparta la atención desde la "placentera" atmósfera nocturna italiana hacia el "verdadero entretenimiento", es decir el acto de contar historias. Una traducción literal del título (Las noches placenteras) habría sugerido interpretaciones orientadas hacia un contenido erótico que convenía exorcizar: si bien los sinónimos agradable y placenteras no admiten ambigüedades semánticas, su combinación con la pareja damas y galanes o con el sustantivo noches podría aludir al tema de la lujuria. El uso del adjetivo honesto le otorga al conjunto un sentido de pudor que también buscó Luis Gaitán de Vozmediano al traducir la Primera parte de las Cien novelas de Giraldi Cintio ${ }^{26}$. El mismo Vicente de Millis Godínez se preocupó de obtener un texto decoroso al traducir al español las Historias trágicas exemplares a partir de una edición francesa de las novelle de Matteo Bandello, ya abundantemente revisada por Boaistuau y Belleforest. La perífrasis elegida por Truchado parece permitir al baezao escaparse también del uso del lexema 'novela' - considerado malicioso, después de Boccaccio- y con este plan acercarse al recurso de Timoneda, que al titular su obra El patrañuelo probablemente quiso esconder el real contenido de la misma ${ }^{27}$.

Ya hemos dicho que la versión de Truchado no respeta fielmente el orden decidido por Straparola: el traductor reduce las «noches» de un número de trece a doce, apuntando la secuencia original y fundiendo algunos elementos de las dos últimas «noches» italianas en su final. Asimismo promete una Tercera Parte que posiblemente podía realizarse a partir de las novelle que no tradujo ${ }^{28}$. La Segunda Parte se concluye con veintisiete tropelías, es decir juegos pirotécnicos de magia que nada tienen que ver con la recopilación de Straparola.

Pasando al texto, nótese que la traducción del prólogo pone en evidencia la inclinación a la amplificatio de Truchado. En esta introducción no se nota ninguna censura, pero las digresiones de Truchado disminuyen aún más un marco narrativo ya originariamente precario por la endeblez estructural del proemio italiano, causada - como ya subrayó Pirovano ${ }^{29}$ - por «lo scarto rispetto alla logica spaziotemporale, visto che una descrizione tipicamente primaverile [...] viene piegata a un ambiente invernale». Esta propensión -sea en el sentido de la amplificatio sea en el

\footnotetext{
${ }^{26}$ Una muestra de los paratextos de las traducciones de los novellieri en España se halla en D. González Ramírez (2012).

${ }^{27}$ A. Guarino (1993), p. 56.

${ }^{28}$ Sobre esta conclusión cf. M. Federici (2011), vol. I, p. 35, ahora en F. Truchado (2014), p. 48.

${ }^{29}$ Straparola (2000), pp. XVI-XX.
} 
de la endeblez literal- se nota también en algunos cuentos que el traductor decide continuar. Algunos ejemplos se encuentran en los diálogos del cuento de Escarpafico (I:3), en la novella de los dos soldados, el alemán y el español (V:3), en la de Plutón villano (V:4), en la de Gáspar médico (V:5) -donde se añaden también dos juegos de composición poética-, en la de Policena y Pámphilo (VIII:5), en la de César napolitano (XII:1), y por último en la de los dos truhanes (IX:4), donde se reducen a dos los tres personajes originales, y en la prosecución de Truchado se olvida el motivo inicial del anillo, construyendo un cierre de débil estructura ${ }^{30}$.

Un ejemplo de autocensura en la traducción se halla en el cuento de Dimitrio y Policena (I:5). Esta novella trata del adulterio de una mujer con un «ciudadano», que en realidad en Le piacevoli notti es un cura. Se elimina así una peligrosa conexión entre el mundo de la Iglesia y la lujuria, probablemente para no ser objeto de censura. Este cambio conlleva una adaptación de la continuación de la novela, que se nota sobre todo en el encuentro entre los dos amantes en la iglesia. Aquí se contrahace totalmente la perspectiva del lector: la mirada de la joven no se dirige al altar sino hacia una imprecisada parte del edificio; las repetidas ojeadas acompañan las «señas con ojo alegre y amoroso melindre», contrariamente al texto italiano; entonces el hombre «se determinó de allí adelante requebralla, y con suabes músicas secretamente servilla», lo que excluye aquel «vagheggiare» a escondidas del texto italiano.

Truchado parece detenerse más en el tema del galanteo privado, mientras que Straparola subraya la recíproca atracción, nacida de las miradas de la mujer al cura, que a menudo sueña ardientemente con ella. Se omite también que Policena «condusse il prete in casa a fare i suoi piaceri», simplemente afirmando que los dos amadores «vinieron en un recíproco amor, y se gozaron el uno y el otro muchos días sin ser sentidos de ninguna persona ${ }^{31}$.

No me detendré mucho en el análisis de los enigmas y de los demás versos, que ya ha sido profundizado en otro trabajo ${ }^{32}$. Basta recordar que respecto a los setenta y cinco enigmas de Le piacevoli notti, la traducción española comprende un total de cincuenta; entre éstos, doce proceden directamente de Straparola. Las adivinanzas italianas tienen dos niveles de significación -uno erótico y otro más sobrio- pero muy a menudo la solución más evidente pertenece al primero de estos niveles. En mi citado artículo opino que los enigmas de Le piacevoli notti omitidos lo fueron por su excesiva explicitud, y que por lo tanto se mantuvieron los de menos alusiones sexuales. Gracias a un análisis léxico de Donald McGrady hoy sabemos que algunos de los enigmas de la compilación de Truchado tienen un sentido indecente, pero más oculto del de la recopilación italiana, preocupándose el baezano

\footnotetext{
${ }^{30}$ Un análisis pormenorizado en F. Truchado (2014), pp. 56-73.

${ }^{31}$ El texto de Le piacevoli notti procede de Straparola (2000), p. 79; el del Entretenimiento de Truchado (2014), p. 169. Las cita proceden siempre de estas ediciones.

${ }^{32}$ Me refiero a M. Federici (2011a).
} 
de que la solución inmediata no pueda atribuirse a la esfera erótica ${ }^{33}$. En la sustitución de los enigmas se suman oportunidades de reducir lo lascivo, de introducir nuevos elementos $\mathrm{y}$, tal vez, dificultades en la traducción poética. Recuérdese que las demás composiciones en verso no proceden de Le piacevoli notti ni tampoco de la mano de Truchado: se trata de nuevas incorporaciones de la compilación española, y es posible que el Entretenimiento de damas y galanes naciera del trabajo de dos traductores entre ellos independientes, y que Truchado sólo tradujera las novelle.

A tenor de lo dicho, parece que Truchado no quiso seguir la experiencia del Decameron, y aparentemente intentó esconder cualquier señal que hubiera llamado la atención de la censura. Sin embargo, su esfuerzo por verter el texto de Straparola en el marco de la honestidad no es completo: en la novella de Teodosio Simeón (IX:1) no hallamos cambios sustanciales, y el traductor no interviene para censurar el conjuro de la alcahueta Grabina, que recuerda en algunas partes la más célebre evocación de Celestina. Asimismo, en la novela se invocan los demonios Taroque y Astarot: el primero, que no aparece en Straparola, sustituye al italiano Farfarello, un diablo que aparece en la Commedia de Dante (Inf. XXI:123 y XXII:94), mientras que el segundo es un príncipe del Infierno que tenía capacidades miméticas, conocido por ser el enemigo de San Bartolomés ${ }^{34}$.

Otro ejemplo, pero de distinta naturaleza, se halla en la novella de Islota y Lucaferro (VII:3) donde el traductor se demuestra menos decoroso que Straparola al traducir la afirmación eufemística «consumò gli ultimi doni d'amore» (p. 240) en «puso a Islota como el quatro bastos» (p. 438). Esta expresión -en una forma anómala que omite la preposición $d e$ - procede del léxico de los naipes y es un derivado regresivo de bastón que presenta una acepción que lo acerca al léxico erótico como sinónimo de pija: se usa también para aludir al acto sexual de una pareja $^{35}$.

Ejemplos como estos, junto con el aditamento de las tropelías, son elementos que parece no se le escaparon al atento ojo de Juan López de Hoyos. En 1581 el maestro de Cervantes escribía un parecer amonestando que había que censurar algunas partes del libro:

Por mandado de Vuestra Alteza, he visto este libro intitulado Segunda parte del honesto entretenimiento, traduzido de lengua toscana por Francisco Truchado, vezino de la ciudad de Baeça. Él corresponde con su título, porque es como un jardín de honestas fictiones exemplares y de buen discurso. Agora doze años vi la Primera Parte, y con esta queda bien satisfecho a la promessa que el autor hizo. No hallo en él cosa que no sea muy gustosa y de buen ingenio. Van borradas

\footnotetext{
${ }^{33}$ El análisis léxico se halla en McGrady (1984).

${ }^{34}$ F. King (1990), pp. 105-106.

35 J.L. Alonso Hernández (1976), s.v. bastón y Alonso Hernández (1979), pp. 186-187.
} 
algunas palabras por no propias o no castas, algunos renglones enteros, particularmente en las tropelías, que son experiencias o secretos de ocultas philosophías, en las quales dezían que se esperassen signos o planetas, para quitar supresticiones [sic] que dañan y offenden en gran manera. Con borrarlo queda lo demás conforme a su título de honesto entretenimiento, y ansí van borradas de modo que el impressor vea luego lo que va con censura. Por lo qual me paresce ser tal y digno de que Vuestra Alteza le haga esta merced, a quien nuestro Señor por muchos años prospere.

Deste estudio de Madrid, a nueve de Julio de 1581.

Por mandado de Vuestra Alteza, su capellán el maestro Juan López de Hoyos ${ }^{36}$.

Se trata de palabras que siguen los preceptos del Index de Fernando de Valdés (Valladolid 1559), que incluye «Libri de Nigromantia, cum invocatione demonum: vel qui sapiant manifeste heresim, tan latino, quam vulgari sermone» ${ }^{37}$. Pese a esta clara advertencia, la traducción de Truchado se halla sensiblemente censurada sólo por el impresor Luis Sánchez y a partir de la edición de Madrid de 1598. Téngase en cuenta que este fue un año muy significativo en la organización de la censura, ya que «se tomaron acuerdos o se formularon leyes en las Cortes celebradas en Toledo, Coruña, Valladolid y Madrid ${ }^{38}$.

La de Luis Sánchez fue una edición muy cuidada por un artesano que, a partir de 1607, estuvo al servicio del Rey. El impresor era hombre instruido, que no desdeñaba incluir algunas poesías de su propria cosecha entre los preliminares de sus ediciones: es cierto -y se nota también en el Entretenimiento- que Sánchez o sus colaboradores -entre otros Gonzalo de Ayala, secretario de la Hermandad de Impresores- intervenían en los textos corrigiendo y censurando, partiendo de su cultura y de su vena creadora más que del respeto de lo que escribían los autores ${ }^{39}$. De hecho, su edición del Entretenimiento de damas y galanes es la más coherente por lo que concierne a las normas gráficas, y demuestra esmero en los frecuentes casos de corrección.

Lo que no hizo Truchado en las novelle y en las tropelías lo remedió Luis Sánchez: la publicación madrileña se modifica en algunos puntos como en la novella de las tres monjas que compiten por ser Abadesa (VIII:1), donde se censuran las palabras conclusivas de sóror Veneranda al referirse la monja a la vida ultramundana. Lo mismo dígase del discurso de sóror Pacífica, a propósito de la edad y linaje de las demás aspirantes y de la riqueza de la Iglesia. Sigue la censura

\footnotetext{
${ }^{36}$ Honesto y agradable entretenimiento, ed. de Baeza 1581 e $1583 \mathrm{f} . \mathrm{Ll}_{6 \mathrm{v}}$ e f. $\mathrm{Ll}_{7 \mathrm{r}}$. Cursivas mías.

${ }^{37}$ F. Valdés (1559).

${ }^{38}$ A. Sierra Corella (1947), p. 92.

${ }^{39}$ Datos extraídos de J. Delgado Casado (1996), pp. 633-635.
} 
de la novella de Teodosio Simeón y Argentina (IX:1), donde el impresor parece seguir al pie de la letra las advertencias de López de Hoyos, interviniendo en los pasajes que se refieren a magia y conjuros. Cuando Isabela María -mujer de Teodosio- se dirige en la novela a Gravina Cana, «muger muy sabia en el mágico arte y encantamientos» (p. 547), la hechicera le ofrece un fíltro mágico y empieza la preparación de su conjuro, explicándole a la joven cómo portarse. Luis Sánchez censura el diálogo entre las dos mujeres. El impreso madrileño no esconde el hecho de que la vieja encantadora recurriera a un hechizo para hallar al joven Teodosio, pero calla las indicaciones de conducta a las que Isabela María deberá atenerse durante el rito, especialmente cuando se le dice «no temáis de cosa alguna, por fea que sea y abominable que veáis» y «no invoquéis el dulce nombre de Jesús ni de su sanctíssima Madre. Tampoco hagáis señal de cruz en tierra, en ropa ni en vuestra persona» (p. 547). En la parte final de la novela Isabela María revela a su marido cómo quedó embarazada estando él lejos, y le narra que después de mucho rezar un ángel la condujo a él. La introducción a esta breve confesión y su misma narración se omiten, ajustando el texto de manera funcional a las intenciones censorias. No parece una coincidencia que la misma novella -VII:1 en Le piacevoli notti- sufra semejante tipo de censura en la edición veneciana de Daniel Zanetti de 1597. Como Luis Sánchez, Zanetti interviene en los fragmentos que se refieren a la Iglesia o bien a la magia: en concreto, aquí también se omite el conjuro de la hechicera ${ }^{40}$.

Por lo que atañe a las tropelías finales, Sánchez censura desde la número 8 hasta la 11, omitiendo también la 14, y demostrando otra vez que acepta las advertencias de López de Hoyos («van borradas algunas palabras por no proprias o no castas, algunos renglones enteros, particularmente en las tropelías, que son experiencias o secretos de occulta philosophía»).

Omisiones de tipo parecido se encontrarán en la única edición de 1590 de la Primera parte de las Cien novelas, traducción de las Hecatommithi de Giraldi Cintio (1565). Mireia Aldomá García, que hace años cotejó el texto italiano con su traducción española, indica que las cláusulas censuradas en esta recopilación corresponden a descripciones físicas con relación al sexo, y que sufren radicales abreviaciones. Se sustituyen también cuentos que tratan el tema adulterino sin castigar, o bien se censuran los detalles del saqueo del Saco de Roma, donde desaparece toda referencia al soldado alemán cargado de repugnancia contra el Papa $^{41}$.

A pesar de esta censura, notamos que ya bastaron las cautelas de Truchado para impedir que una obra muy parecida en el contenido al Decameron llamara la atención de la Inquisición y se prohibiera por sus aspectos eróticos y sus ribetes heréticos. De hecho, las únicas referencias en tema de prohibición que hemos

${ }^{40}$ D. Pirovano (2001), p. 70-71.

${ }^{41}$ Resumo las palabras del trabajo de M. Aldomá García (1996), pp. 19-21. 
hallado son muy tardías: la primera aparece en el Index de Alejandro VII (1667) ${ }^{42}$; la otra es del siglo XVIII y se encuentra en el Indice último de los libros prohibidos $y$ mandados expurgar (1790), donde se nombra el Entretenimiento de damas y galanes pero en la portada se avisa que el libro «Contiene en resumen todos los libros puestos en el Indice expurgatorio del año 1747, y en los Edictos posteriores, hasta fin de Diciembre de $1789 \gg^{43}$.

Así pues, Truchado triunfó en su intención de eludir la censura, y su libro no tuvo el mismo destino inquisitorial del Decameron, no obstante se parezca en la estructura, en el contenido erótico -sobre todo en los enigmas- y en el pertenecer al sospechoso y lascivo género literario de la novella. Al contrario de los índices españoles, la lista de Parma de 1580 y los índices de Roma de 1590 y 1593 desaprueban Le piacevoli notti de Straparola «quousque ex superioribus regulis

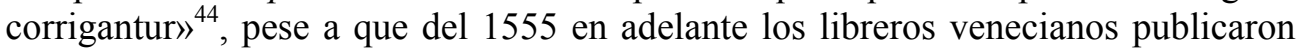
ediciones intentando suprimir lo que pudiera llamar la atención de la Inquisición ${ }^{45}$. De alguna forma la traducción de Truchado y su ruta editorial parece tuvieron como punto de referencia no sólo lo que pasó con el Decameron sino también los acontecimientos censorios de las ediciones italianas de Le piacevoli notti entre 1555 y 1598. La traducción perifrástica del título, la sustitución de los enigmas con otros de sentido erótico más velado, y la autocensura del impresor Luis Sánchez demuestran que Truchado no quiso eliminar totalmente lo lascivo sino esconderlo a lecturas poco atentas, manteniendo de alguna forma el contenido ideal de la obra. En cambio, la conducta del traductor parece seguir el intento de aprender de la escritura y de la labor de traducción de las novelle, y hacer práctica en sus digresiones y añadiduras buscando un estilo propio. En este sentido Francisco Truchado sigue a los imitadores de la tradición italiana de cuentistas y a los traductores europeos de Le piacevoli notti, que muy a menudo sustituían ciertas novelle con nuevas incorporaciones. Pero al mismo tiempo el baezano le da a su Entretenimiento un lugar privilegiado entre las demás traducciones europeas, al ser la española -junto con la francesa- la única que se acerca a la trasposición completa de la recopilación italiana ${ }^{46}$.

${ }^{42}$ En dicho Índice bajo la voz «Honesto, y agradable entretenimiento de Damas y Galanes» aparece: «Vease Iuan Francisco Carbacho, p. 733-col. 2. en Cast.».

${ }^{43}$ A. Rubín Cevallos (1790), p. 46.

44 J. Martínez de Bujanda (1984-2002), vol. IX, p. 158 y pp. 379-380; vol. XI, p. 859.

${ }^{45}$ D. Pirovano (2001), p. 79.

${ }^{46}$ Un buen resumen de las traducciones europeas se halla en Straparola (2000), pp. 814-816. 


\section{Obras citadas}

ALDOMÁ GARCÍA, Mireia: "Los Hecatommithi de Giraldi Cinzio en España", Studia Aurea. Actas del III Congreso de la AISO (Universidad de Toulouse Le Mirail, 1993), ed. de I. Arellano, C. Pinillos, M. Vitse y F. Serralta, Griso/Lemso, Navarra/Toulouse, 1996, vol. III, pp. 15-22.

Alonso Hernández, José Luís: Léxico del marginalismo del Siglo de Oro, Salamanca, Universidad, 1976.

-----: El lenguaje de los maleantes españoles de los siglos XVI y XVII: La Germanía, Salamanca, Universidad, 1979.

Alonso, Amado: "Lope de Vega y sus fuentes", Thesaurus. Boletín del Instituto Caro y Cuervo, XLVIII, 2, (1993), pp. 3-26.

Alvar, Carlos: "Boccaccio en Castilla: entre recepción y traducción", Cuadernos de Filología Italiana, Núm. Extraordinario, (2001), pp. 333-350.

ARRÓNIZ, Othón: La influencia italiana en el nacimiento de la comedia española, Madrid, Gredos, 1969.

BARANDA, Nieves: "Literatura en sociedad. Dos tratados italianos de saber vivir en la Andalucía de la Contrarreforma", Spagna e Italia attraverso la letteratura del secondo Cinquecento, ed de E. Sánchez García, A. Cerbo y C. Borrelli, Napoli, L'Orientale, 2001, pp. 302-320.

Bongi, Salvatore: Novelle di M. Antonfrancesco Doni. Colle notizie sulla vita dell'autore raccolte, Lucca, Fontana, 1852.

Bourland, Caroline Brown: "Boccaccio and the Decameron in Castilian and Catalan literature", Revue Hispanique, XII, (1905).

BRADBURY, Gail: "Lope Plays of Bandello Origin", Forum for Modern Language Studies, 16, (1980), pp. 53-65.

BRANCA, Vittore: "Boccaccio protagonista nell'Europa letteraria fra tardo Medioevo e Rinascimento", Cuadernos de Filología Italiana, Núm. Extraordinario, (2001), pp. 21-37.

CÁTEDRA, Pedro María: Imprenta y lecturas en la Baeza del siglo XVI, Salamanca, SEMYR, 2001.

Chevalier, Maxime: "Sobre un apólogo de Guzmán de Alfarache", Cuento tradicional, cultura, literatura (Siglos XVI-XIX), Salamanca, Universidad, 1999, pp. 153-158.

COPPOLA, Leonardo: "Traducción y dispositio: Truchado y Le piacevoli notti", Dicenda. Cuadernos de Filología Hispánica, XXX, Núm. Especial, (2012), pp. 141-152.

-----: "Prolegómenos a la edición del Honesto y agradable entretenimiento de damas y galanes", Pictavia aurea. Actas del IX Congreso de la Asociación Internacional "Siglo de Oro" (Poitiers, 11-15 de julio de 2011), dirigido por A. Bègue y E. Herrán Alonso, Université de Toulouse-Le Mirail, Presses Universitaires du Mirail, 2014, pp. 367-374. 
CROS, Edmond: Contribution à l'étude des sources de Guzmán de Alfarache, Montpellier, Bibliothéque Municipale, 1971.

Delgado Casado, Juan: Diccionario de impresores españoles (Siglo XV-XVII), Madrid, Arco, 1996.

DI PINTO, Elena: "De cuernos y de celos: un problema de intertextualidad entre Straparola, Bandello y Cervantes (el dulce novelar de los tres autores)", Amor y Erotismo en la Literatura. Congreso Internacional Amor y Erotismo en la Literatura (Salamanca, 1998), ed. de V. González Martín, Salamanca, Caja Duero, 1999, pp. 267-276.

FEDERICI, Marco: "Cervantes lettore di fiabe? Il furto dell'asino nella Sierra Morena", Rivista di Filologia e Letterature Ispaniche, XIII, (2010), pp. 6775.

-----: Edizione di Francisco Truchado, «Honesto y agradable entretenimiento de damas y galanes», Tesis Doctoral, Università di Roma "La Sapienza". Tutor prof. N. von Prellwitz (Tesis defendida el día 13 de mayo de 2011 y depositada en el Archivo digital PADIS. Estudio preliminar y edición completa en tres volúmenes en http://padis.uniroma1.it/handle/10805/1016).

-----: "La traduzione e la ricezione degli enigmi de Le piacevoli notti nella Spagna del XVI secolo", Rivista di Filologia e Letterature Ispaniche, XIV, (2011a), pp. 9-30.

-----: "Un viaje de despedida: intromisiones en Le piacevoli notti españolas", ponencia leída el día 29 de mayo de 2014 en el Congreso Internacional Viaggi rari. Letterature iberiche, letterature comparate, coord. por G. Grilli (Roma, Università degli Studi di Roma Tre, 28-30 de mayo de 2014).

GasparetTI, Antonio: "G. B. Giraldi Cinzio e Lope de Vega", Bulletin Hispanique, XXXIV, (1930), pp. 372-404.

-----: Las «Novelas» de Mateo Bandello como fuentes del teatro de Lope de Vega Carpio, Salamanca, Universidad, 1939.

GÓMEZ BEDATE, Pilar: "Traducir a Boccaccio: noticia sobre mi traducción del Decameron (Barcelona, 1983)", Il viaggio della traduzione. Actas del congreso coord. por M. G. Profeti (Florencia, 13-16 giugno 2006), Firenze, Firenze University Press, 2007, pp. 299-312.

GONZÁLEZ DE AMEZÚA, Agustín: Formación y elementos de la novela cortesana, Madrid, Archivos, 1929.

GONZÁLEZ RAMIREZ, David: "En el origen de la novela corta del Siglo de Oro: los novellieri en España”, Arbor: Ciencia, pensamiento y cultura, 752, (2011), pp. 1221-1243.

-----: "La «princeps» del Honesto y agradable entretenimiento de damas y galanes (Zaragoza, 1578) de Straparola: hallazgo de una edición perdida", Analecta Malacitana: Revista de la Sección de Filología de la Facultad de Filosofia y Letras, XXXIV, 2, (2011a), pp. 517-528. 
-----: "En el origen de la novela corta del Siglo de Oro: los novellieri desde sus paratextos", Arbor: Ciencia, pensamiento y cultura, 756, (2012), pp. 813828.

GUARINO, Augusto La narrativa di Joan Timoneda, Napoli, Istituto Universitario Orientale, 1993.

GÜNTERT, Georges: "Cervantes, lector de Boccaccio: Huellas y reflejos de la «X Giornata» del Decamerón en las Novelas ejemplares", Actas del V Congreso Internacional Siglo de Oro (Münster, 20-24 de julio de 1999), ed. de C. Strosetzki, Frankfurt am Main-Madrid, Vervuert/Iberoamericana, 2001, pp. 680-690.

HERnÁNDEZ esteban, María: "Juan de Almeida", en Jauralde Pou, Pablo (dir.), Diccionario Filológico de Literatura Española. Siglo XVI, Madrid, Castalia, 2009.

-----: "El cuento 73 de Las cien novelas de Juan Bocacio ajeno al Decameron", Dicenda. Cuadernos de Filología Hispánica, XX, (2002), pp. 105-120.

Index librorum prohibitorum Alexandri VII, Pontificis Maximi, Romae, ex Typographia Rev. Cam. Apost., M.D.C.LXVII.

KING, Francis: Il cammino del serpente, Roma, Mediterranee, 1990.

KOHLER, Eugène: "Lope de Vega et Giraldi Cinzio", Mélange 1945. II: Etudes littéraires, Paris, Les Belles Lettres, 1946, pp. 169-260.

LACARRA, María Jesús: "De la mujer engañadora a la malcasada ingeniosa. El cuento de «El pozo» (Decamerón VII, 4) a la luz de la tradición", Cuadernos de Filología Italiana, Núm. Extraordinario, (2001), pp. 393-414.

LASPÉRAS, Jean-Michel: La nouvelle en Espagne au Siecle d'Or, Perpignan, Castillet, 1987.

LEVI, Ezio: Lope de Vega e l'Italia, Firenze, Sansoni, 1935.

LuCÍA Megías, José Manuel y SAMA RoJo, Valentín: "Bibliografía 1975-2000", Cuadernos de Filología Italiana, Núm. Extraordinario, (2001), pp. 575-602.

MARCELLO, Elena: "Sulla diffusione e traduzione delle novelle di G. F. Straparola in Spagna I - La novella VI, 1", La traducción en las relaciones italoespañolas: lengua, literatura y cultura, ed de A. Camps, Barcelona, Universitat de Barcelona, 2012, pp. 171-185.

-----: "Sobre la traducción española de Le piacevoli notti de G.F. Straparola. Antígrafo, configuración de la obra y autocensura en Francisco Truchado", Revista Hispanista Escandinava, 2, (2013), pp. 48-65.

MARTíNEZ DE BUJANDA, Jesús (dir.): Index de livres interdits, Sherbrooke-Genève, Centre d'études de la Renaissance, Université de Sherbrooke-Librairie Droz, 1984-2002.

MCGRADY, Donald: "Notas sobre el enigma erótico, con especial referencia a los Cuarenta enigmas en lengua española", Criticón, 37, (1984), pp. 71-108.

MENÉNDEZ Y PELAYO, Marcelino: Origenes de la novela, ed. de E. Sánchez Reyes, Madrid, CSIC, 1962. 
MetForD, John Callan James: "Lope de Vega and Boccaccio's Decameron", Buletín Hispanic Society, XXIX, (1952), pp. 75-85.

PEDROSA, José Manuel: Las dos sirenas y otros estudios de literatura tradicional, Madrid, Siglo XXI, 1995.

-----: El cuento popular en los Siglos de Oro, Madrid, Laberinto, 2004.

PÉREZ PRIEGO, Miguel Ángel: "Boccaccio en la obra literaria de Santillana", Cuadernos de Filología Italiana, Núm. Extraordinario, (2001), pp. 479-495.

PIRovano, Donato: "Una storia editoriale cinquecentesca: Le piacevoli notti di Giovan Francesco Straparola", Giornale storico della letteratura italiana, CLXXVII, 580, (2000), pp. 540-569.

-----: "Per l'edizione de Le piacevoli notti di Giovan Francesco Straparola", Filologia e Critica, XXVI, (2001), pp. 60-93.

ROMERA PINTOR, Irene: "De Giraldi Cinthio a Lope de Vega: red intertextual en $L a$ cortesía de España", Otro Lope no ha de haber. Actas del Congreso Internacional sobre Lope de Vega, coord. por M. G. Profeti, Firenze, Alinea, 2000, pp. 33-48.

Rubín Cevallos, Agustín: Indice último de los libros prohibidos y mandados expurgar: para todos los Reynos y Señorios del católico Rey de las Españas, el Señor don Carlos IV, Madrid, en la imprenta de Antonio de Sancha, 1790.

SABBA Da CASTiglione: Parte primera del Cauallero Auisado: en la q[ua]l con prudente y Christiano discurso, se tracta d[e] todo lo que deue hazer el hombre para ser auisado, Compuesta por Monseñor d[e] Sabaa [sic], Castellon: cauallero d[e] la orden d[e] sant Iuan; y traduzida por Francisco Truchado, Impresso en Baeça, en casa d[e] Iuan Baptista de Montoya, 1585.

SEGRE, Cesare: Da Boccaccio a Lope de Vega: derivazioni e trasformazioni, Ravenna, Longo, 1975.

SENN, Doris: "Le Piacevoli notti (1550/53) von Giovan Francesco Straparola, ihre italienischen Editionen und die spanische Übersetzung Honesto y agradable entretenimiento de damas y galanes (1569/81) von Francisco Truchado", Fabula, XXXIV, 1-2, (1993), p. 45- 65.

SIERRA CORELla, Antonio: La censura de libros y papeles en España y los índices $y$ catálogos españoles de los prohibidos y expurgados, Madrid, Cuerpo Facultativo de Archiveros, Bibliotecarios y Arqueólogos, 1947.

StraPAROlA, Giovan Francesco: Le piacevoli notti, ed. de D. Pirovano, Roma, Salerno, 2000.

TRUCHADO, Francisco, Honesto y agradable entretenimiento de damas y galanes, ed. de M. Federici, Roma, Nuova Cultura, 2014.

VALDÉS, Fernando de: Cathalogus librorum, qui prohibentur mandato Illustrissimi \& Reverend. D. D. Ferdinandi de Valdes Hispalen. Archiepis. Inquisitoris Generalis Hispaniae, Hoc anno M.D.LIX editus, Sebastianus Martinez Excudebat, Pinciae. 
VALVASSORI, Mita: "Observaciones sobre el estudio y la edición de la traducción castellana antigua del Decameron", Cuadernos de Filología Italiana, Volumen Extraordinario, (2010), pp. 15-27. 